\title{
The fluctuation of the beginning time of flood season in North China during AD1766-1911
}

\author{
Wei Pan ${ }^{\mathrm{a}, \mathrm{b}}$, Jie Fei ${ }^{\mathrm{c},}{ }^{*}$, Zhimin Man ${ }^{\mathrm{c}}$, Jingyun Zheng ${ }^{\mathrm{b}}$, Hongzhong Zhuang ${ }^{\mathrm{c}}$ \\ a Center for Historical Environment and Socio-Economic Development in Northwest China of Shaanxi Normal University, Xi'an, Shaanxi 710062, China \\ ${ }^{\mathrm{b}}$ Institute of Geographic Sciences and Natural Resources Research, CAS, Beijing 100101, China \\ ${ }^{\text {c } C e n t e r ~ f o r ~ H i s t o r i c a l ~ G e o g r a p h y ~ S t u d i e s ~ o f ~ F u d a n ~ U n i v e r s i t y, ~ S h a n g h a i ~ 200433, ~ C h i n a ~}$
}

\section{A R T I C L E I N F O}

\section{Article history:}

Available online 22 October 2014

\section{Keywords:}

Yellow River

Yongding River

Qinhe River

Flood season

Climate change

\begin{abstract}
A B S T R A C T
This study is based on the Qing government water level gauge records from Wanjingtan of the Sanmenxia Gorge in the middle reaches of the Yellow River, Muluandian in the lower reaches of Qinhe River, and Shijingshan and Lugou Bridge in the lower reaches of Yongding River. The beginning of the flood season has been reconstructed. The anomaly series of the flood season is assessed using pentad scales. The sequence represents the middle reaches of the Yellow River, the lower reaches of the Qinhe River, and the lower reaches of Yongding River. Within the research period, the middle reaches of the Yellow River and the lower reaches of the Qinhe River began the flood season on 6-10 July on average, and Yongding River began 16-20 July. The Yongding River is relatively stable and the start of rainy season of its upstream was basically maintained in early July. The middle reaches of the Yellow River and the lower reaches of the Qinhe River show great fluctuation, with discrepancies up to 3 months. The same anomalous fluctuation in the flood season of the middle reaches of the Yellow River and the Qinhe River is more obvious after the mid-19th century. The delay of flood season by about one pentad in the middle reaches of the Yellow River, Qinhe River, and Yongding River is in accordance with the relative low temperature of the Loess plateau in summer, while the early flood season of the middle reaches of the Yellow River and Qinhe River corresponds with the relative high summer temperature in the Loess Plateau. The beginning time of the flood season in the research area is the time the rainy season begins. The length of summer-monsoon rainy season during 1860s-1940s has been reconstructed, as the Little Ice Age transformed to the Modern Warm Period in China. Rapid warming could change the summer rainy season by $2-3$ pentads.
\end{abstract}

\section{Introduction}

The Asian Monsoon plays an important role in transporting large quantities of heat and moisture to the most-populated regions of the world. Precipitation and the dare of first rain are sensitive to the East Asian Summer Monsoon (EASM) intensity (An, 2000). The rainy season related to EASM has great significance for annual precipitation over northern China (He et al., 2007). The starting date of the rainy season is critical for crop planting and yields (Griffiths, 1994; Tao et al., 1997; Zhu et al., 2011), and changing EASM leads to the changing dates of the river flood season. In this article, three rivers in semi-humid northern China were

\footnotetext{
* Corresponding author.

E-mail address: jiefei@fudan.edu.cn (J. Fei).
}

chosen to study the change of timing of the flood season related to the EASM from 1766 to 1950 (Fig 1).

Rain-fed agriculture is the most important part of the economy of China during the past thousands of years. Rainy summers and autumns lead to river floods, and throughout Chinese history government has had to manage flooding to avoid agricultural loss. The Yu-Xue-Fen-Cun (YXFC, Yu/rainfall-Xue/snowfall-Fen/Chinese length unit, approximately $0.32 \mathrm{~cm}$-Cun/10Fen, $3.2 \mathrm{~cm}$ ) archives of Qing Dynasty (1644-1911) were used to reconstruct the precipitation in the middle-lower reaches of Yellow River, and the rain dates in the semi-arid region of North China (Zheng and Wang, 2005; Ge et al., 2011).

In the early 18th century, the Qing government (1644-1912) began to set up water level observation stations on rivers in China. The water level observation station at Wanjintan is on the Yellow river, north of Laoxiancheng, Shanxian county, Sanmenxia city, 


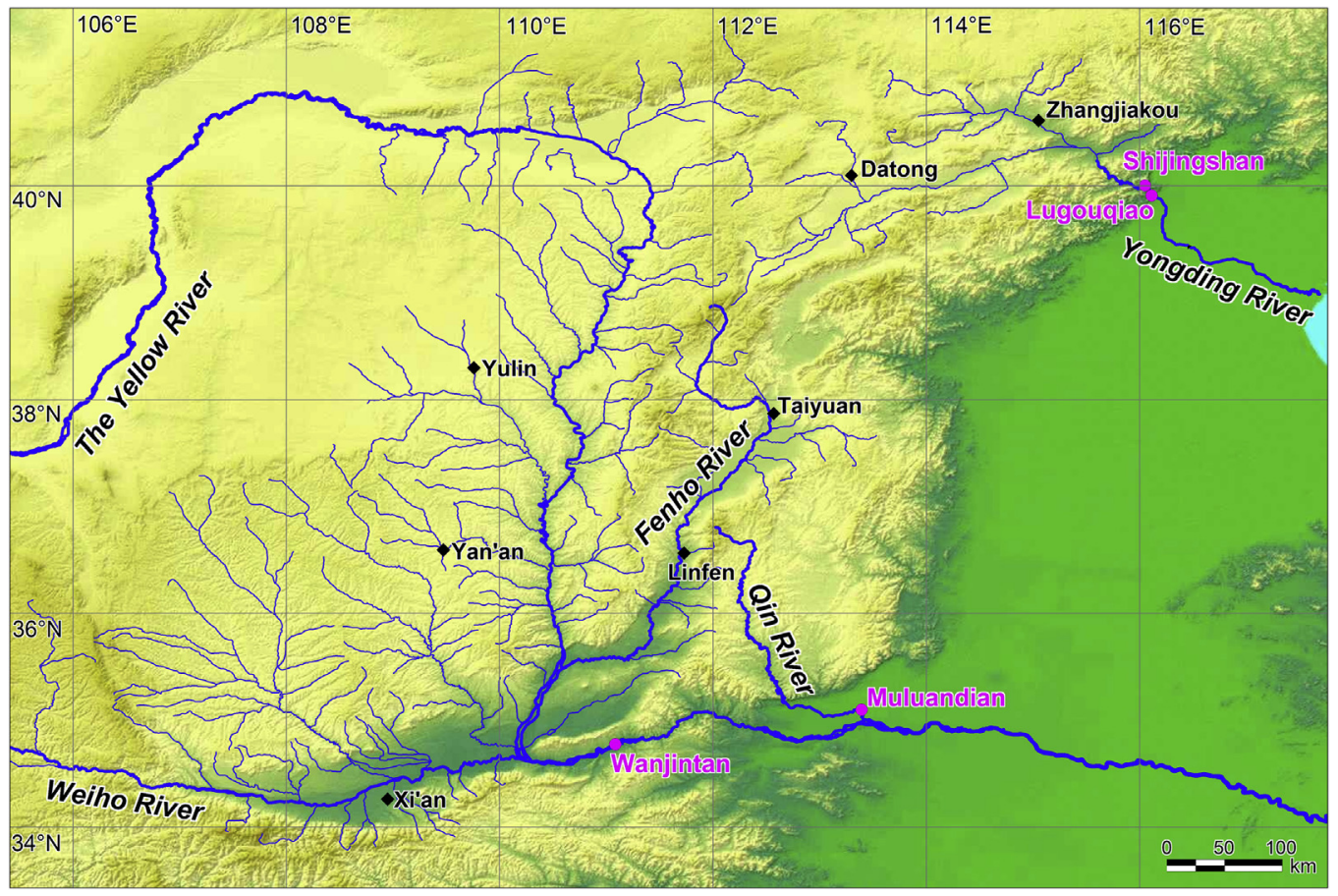

Fig. 1. Study area.

Henan province. It is an important data source for monitoring the water conditions of the middle reaches of the Yellow River. Similarly, there are observation stations on the Qinhe River and Yongding River, located at Muluandian in Wuzhi County and Shijingshan-Lugouqiao, respectively. According to the rules of Qing Dynasty, when the water level rises $2 \mathrm{Chi}$ (Chi is a Chinese length unit; 1 Chi $=0.32 \mathrm{~m}$ ) or more, the date and height must be reported to the imperial government. At present, these reports are scattered through the following sources: 'Extracts of the water condition of historical floods in Qing Dynasty at Wanjintan and Xiakou on the Yellow River; Muluandian on the Qinhe River; and Gongxian on the Yiluo River', edited by the Yellow River Conservancy Commission in the 1980 s as internal documents.

\section{Methods}

The first date of rising water was converted to pentad-scale, that is to say, July 1 is converted to $7 / 1$, i.e. the first pentad in July. The method of assessing the dates of flood season on the pentad-scale was used in a similar study of the rainy season start date during 1644-1911 (Yang et al., 2007). Use of historical documents is especially suitable for such studies. Pan et al. (2012) studied the annual dates of first rising water at the Wanjintan station on the Yellow River. In light of their conclusion, the average beginning time of flood season in the Sanmenxia Region was July 6-10 during 1766-1911. This date corresponds with the date of the last stage of Meiyü (plum rain) in the middle and lower reaches of the Yangtze River (Ge et al., 2008). When the summer rain-belt moves northward into the Huanghe River valley and North China, the rivers enter flood season in these areas. It agrees with the process of the summer rain-belts, so it should be possible to convert the annual first water rising dates to pentad scale.

The Qing Dynasty (AD 1644-1912) was concerned with weather, hydrological events, droughts, and floods. The empire constructed a very efficient recording system using reports from officers and regional intellectuals. Three kinds of archives are very important to this paper. 1) Water level records of the Qing government from the early 18th century; 2) Yu-Fen-Cun (YFC), recording the beginning/ending dates, duration and rainfall infiltration depths into soil for individual precipitation events; and 3) Hydrological records for 1912-1950.

\section{Results and analysis}

\subsection{Fluctuation of the beginning time of flood season}

According to the average situation of the reconstruction, the beginning times of flood seasons of both the Yellow River and Qinhe River range from July 6 to July 10 . Meanwhile, the flooding season of the Yongding River begins a little later, and ranges from July 16 to July 20 . Here, we reconstruct the chronology of the beginning of the flood season of the three rivers on a pentad scale. The standard deviations of Yellow River, Qinhe River and Yongding River are $1.19,1.01$ and 0.64 , respectively. There are significant fluctuations in the Yellow River's flood season, and the Qinhe River shows significant instability in its flood season. By comparison, the Yongding River is the most stable one, which shows that the rainy season in the northern Loess Plateau during the Qing Dynasty was relatively stable. Fig. 2 shows the 5-point smoothing average curve of the beginning time of the flood season. Except for an evident fluctuation between 1880 and 1890, the Yongding River's flood season has changed very little.

Table 1 shows the extreme value of the date of flood season initiation. All of the extreme events occurred in the period without modern weather and hydrological records. $1842 / 3-2$ is the second pentad in March AD1842 (6-10th March). The extreme value of the flood season dates for the middle reaches of the Yellow River is much larger than for the Qinhe and Yongding Rivers. That was the period when flood disasters along the Yellow River occurred most frequently and severely in eastern Henan Province. At that time, 


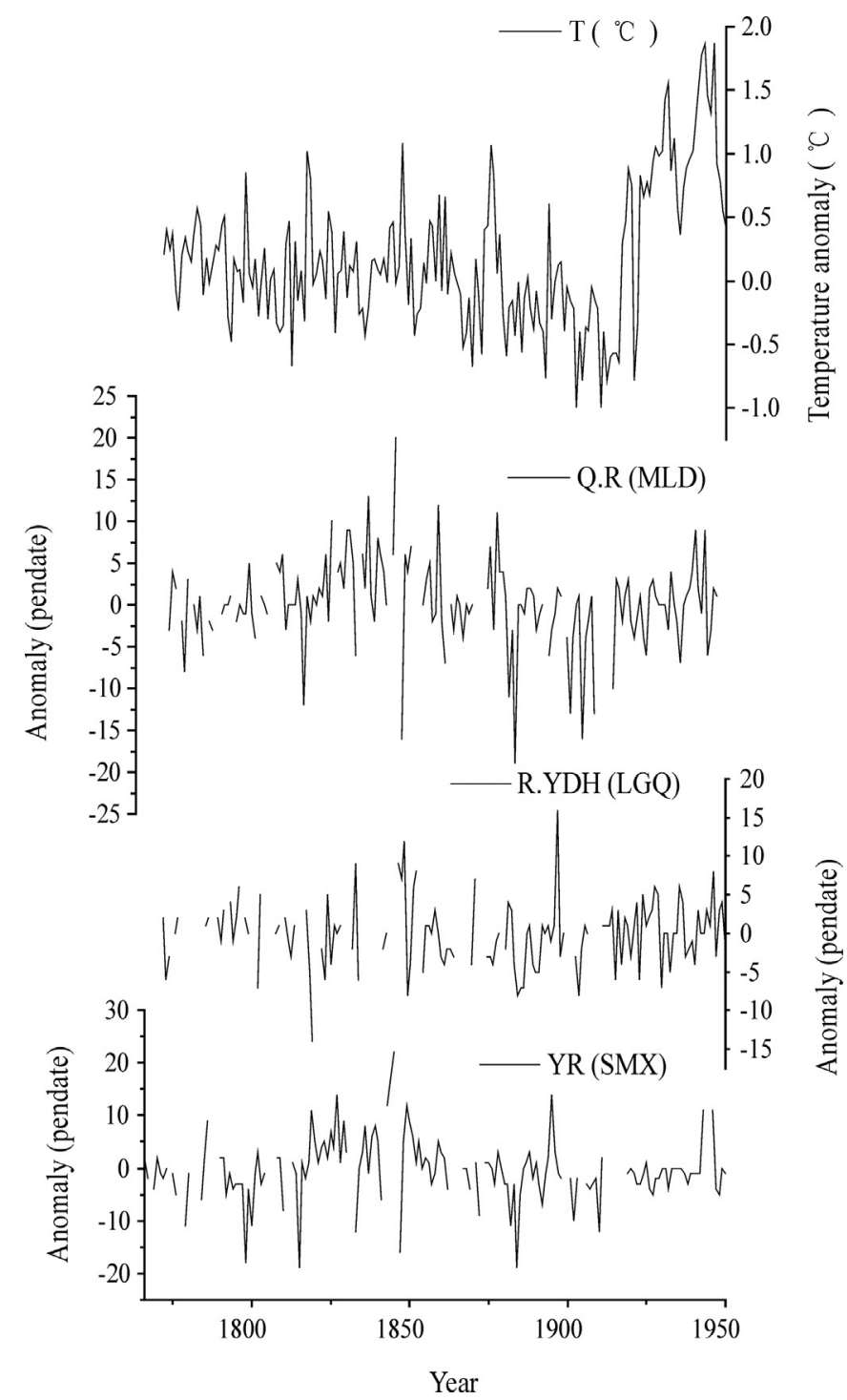

Fig. 2. Time fluctuations of Yellow River (Sanmenxia), Qinhe River, Yongding River beginning flood season and anomalies of warm/cold fluctuations in the Loess Plateau during AD 1766-1950.

the average flood season initiation date in the Sanmenxia Region was 7 days earlier. In the flood years of 1841, 1842, 1843, 1849, and 1850 , the flood appeared in early May or even earlier, except during 1841, 5-10th August. The lengthy flood seasons in 1842 and 1845 even began in early March. From the mid-18th century to the early 20th-century, this phenomenon only happened two times. It might be due to the abnormal high amount of rainfall in the middle reaches of the Yellow River in the spring. The flood season date was generally in the middle of October in the middle reaches of the Yellow and Qinhe River, and in the middle of August in the Yongding River. The middle reaches of Yellow River and Qing River are affected by Bay of Bengal moisture which is carried by southwest monsoon winds in September. Both areas are affected by the autumn rain season, and the flood season in October is the manifestation of strong southwest monsoon winds. The upper reaches of the Yongding River is out of the influence of southwest monsoon wind, so the main reason of stabilization of Yongding River's flood season is that the flood season is concentrated in summer.
Table 1

Extreme values of flood season initiation

\begin{tabular}{lll}
\hline River & Earliest & Latest \\
\hline Yellow River (Sanmenxia) & $1842 / 3-2$ & $1884 / 10-2,1798 / 10-2$ \\
Qinhe River & $1824 / 5-2$ & $1815 / 10-3,1884 / 10-3$ \\
Yongding River & $1738 / 5-6$ & $1745 / 8-5$ \\
\hline
\end{tabular}

On the whole, the flood season of the Qinhe River and the middle reaches of the Yellow River was advanced by about 5 days during the 1810-1870s. The flood season of the Qinhe River, the middle reaches of the Yellow River, and Yongding River was delayed for about 5 days in the 1880s. In the 20th century, the flood season of the Qinhe River was delayed, while those of the middle reaches of the Yellow River and the Yongding River advanced.

\subsection{Warm/Cold periods and the beginning of flood season}

Ge et al. (2003) reconstructed the inter-decadal resolution chronology of winter temperature fluctuations of the middle and lower reaches of the Yangtze River and Yellow River over the past 2000 years. The cold period of the $1870-1880$ s was a cold peak during the 1750-1910s period, which corresponded to the delayed flood season. Using the historical documents and tree-ring records of the Loess Plateau, Yi et al. (2012) reconstructed a new summer temperature chronology (Fig. 2). The cold period of the 1870-1880s is also apparent, and it did not become warm until the 1920s, which was nearly 20 years later than the average time of the end of the Little Ice Age in the Northern Hemisphere. Fig. 2 shows the comparison of the beginning time of flood season in the middle reaches of the Yellow River and the Qinhe River and the Yongding River with the fluctuation of the summer temperature of the Loess Plateau. The 1880s was the period when the flood season of the rivers was delayed, corresponding to the winter temperature "cold period' of the monsoon area of eastern China and the sharp cooling process of the loess plateau that began in the 1870s. The summer temperature of the loess plateau was high in the 1820s through 1860s, which corresponds to advanced flood seasons of the Yellow River and the Qinhe River. The 1850-1860s were marked by the rising stage of winter temperature which was opposite to the trend of summer temperature change of the loess plateau (Ge et al., 2003). Along with the $0.5 \mathrm{C}^{\circ}$ decline of the summer temperature of the loess plateau in the 1860s, the flood season of the Qinhe River and the Yellow River was delayed by about a pentad.

\subsection{EASM change and the beginning of flood season}

The rainy season related to the East Asian Summer Monsoon (EASM) has great significance for annual precipitation in China. In particular, a stronger EASM is accompanied by decreased rainy days and precipitation amount over the region of the Huaihe River and the middle and lower reaches of the Yellow River (Zhang and Liu, 2003; Zhang et al., 2003a,b; Zhu et al., 2005), while such conditions tend to result in more rainy days and precipitation amounts over northern China (Guo et al., 2004). The intensity of the EASM is an important factor influencing the rainfall pattern over eastern China. In the years of strong summer monsoon, the rainbelt rushes quickly over northern China and causes drought in the Yangtze River Valley and wetness along the northern boundary of the EASM (Tao and Chen, 1987). As the intensity of the EASM is significant in determining the northern extension of the summer monsoon, it is reasonable to conclude that the intensity of the monsoon is related to the beginning of the flood season in this 


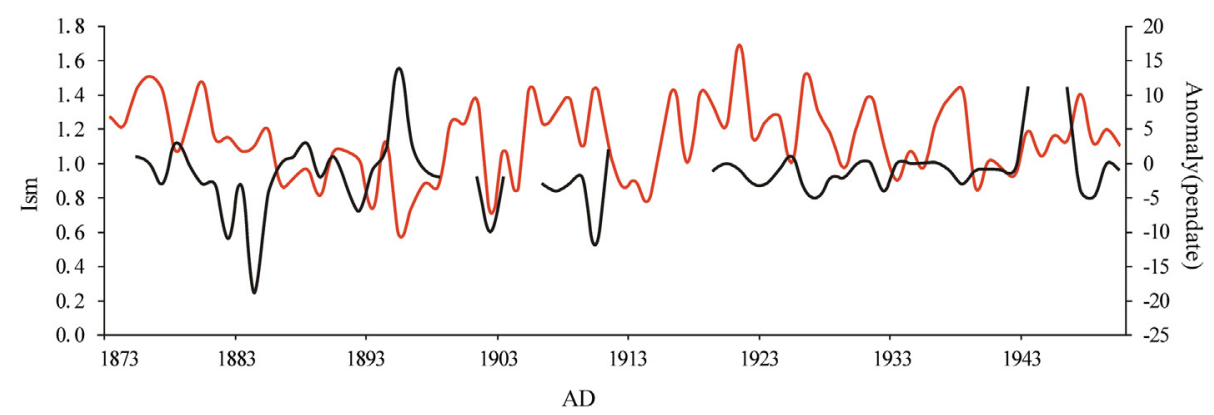

Fig. 3. Relationship between time fluctuation of Yellow River (SMX) and the Ism.

area. Different authors have developed several indices to describe the weak/strong fluctuation of EASM(EASMI) (Guo, 1983; Tao et al.,1987; Zhao and Zhang, 1996; Shi and Zhu, $1996 \mathrm{Lu}$ and Chan, 1999; Sun et al., 2001; Wang, 2001; Zhang and Liu, 2003; Zhang et al., 2003a, b; Guo et al., 2004; Huang, 2004; Lian et al., 2004; Lee et al., 2005; Zhao and Zhou, 2005; Zhu et al., 2005). Guo et al. (2004) reconstructed the index of summer monsoon (Ism) on the basis of the sea level pressure record (SLP) from 1873 to 2000. Fig. 3 shows the relationship between the Ism and the flood season beginning for the Yellow River (Sanmenxia). The weak summer monsoon is the main cause of the delayed flood season of the middle Yellow River and the Qinhe River and Yongding River under the abnormally cold background in the 1880s. The mid1880 s to 1900 s was the period when the summer monsoon is weak, which corresponded to the delayed flood season. This phenomenon is also reflected in the monsoon duration in northern Shanxi and Shaanxi Provinces.

\subsection{Summer-monsoon rain-band movement in central China}

Ge et al. (2003) revealed that the monsoon duration of Taiyuan, Datong and Yulin during 1736-2000 was 10-20 days shorter than that of the 1860s-1900s. According to the above two phenomena, as well as the phenomenon that the flood season advances for about 5 days, it can be deduced that the phenomenon of the weaker summer monsoon of the 19th century caused a delayed rain belt in the entire loess plateau. The earlier flood season in the 1820 s -1860 s also agrees with the strong summer monsoon. The summer monsoon was strong according to the length variability of meiyu (plum rain) period in the middle and lower reaches of the Yangtze River since 1736. The flood season of the middle reaches of the Yellow River and the Qinhe River is also earlier.

This data can be combined with the other series or proxy about rain-band in several areas over China, including the South Rim of Plum Rain in Xiangjiang River (SR), one tributary of Yangtze River, locate in Hunan Province China, the typical Plum Rain Area along the middle reaches of Yangtze River (MRYZR), and the middle reaches of Yellow River (MRYR). Zheng (2010) reconstructed the beginning/end dates of the rainy season over SR since 1861 based on diaries and weather records. The changing of typical Plum Rain and the end dates of the rainy season over MRYR in the last 300 years has already been reconstructed (Ge et al., 2008, 2011).

The average lengths of the Plum rain period and summer rainy season over SR, MRYZR and MRYR is 3.5,5 and 10 pendates in past 150 years, respectively. Compared to the annual length for the three areas during 1860-1890s and 1920-1930s (Fig 4), the length of rainy season over MRYR became shorter, while the SR became longer. The rain belt shifted south to the SR, and North China became drier. The 2 important and serious drought disasters in 1877-1878 and 1928-1929 in MRYR can be found in Fig 4. The summer monsoon rain remained over MRYZR for too long, and the stay over MRYR was very short. The southern shift of the summer
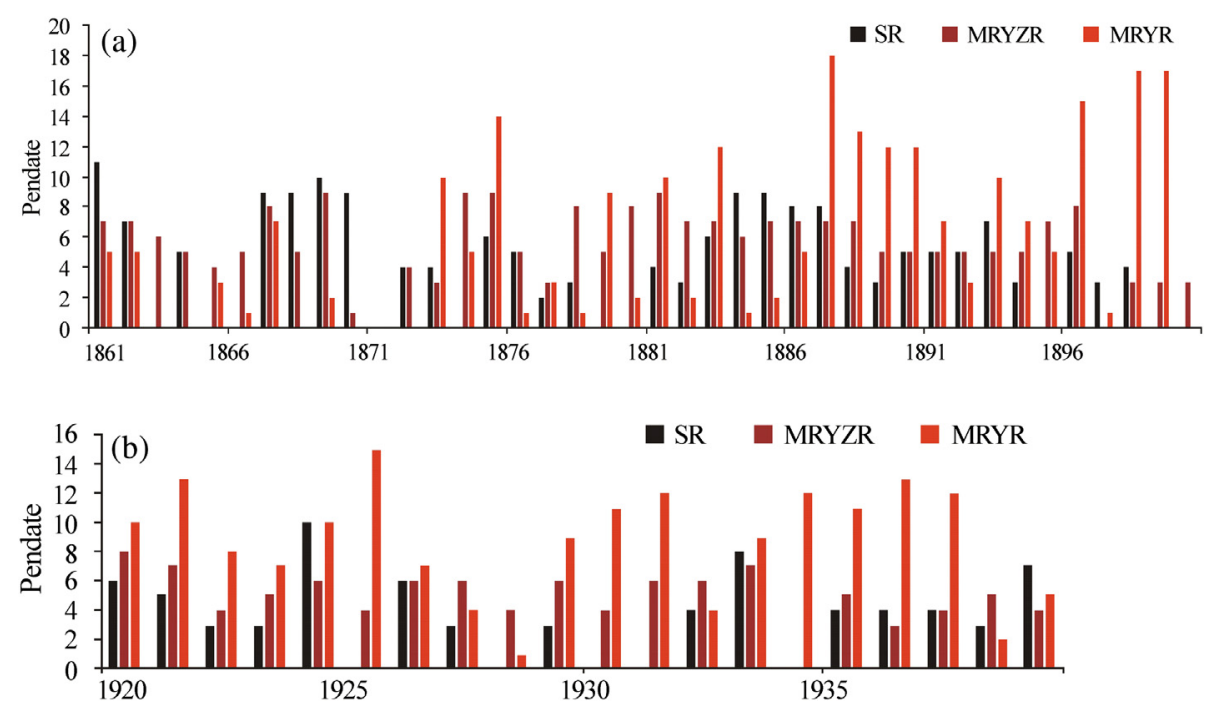

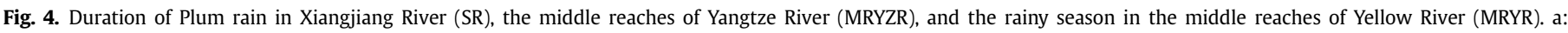
1861-1899; b: 1920-1940. 
rain-band is more clear on an inter-decadal scale (Table 2). The 1860-1930s was a rapid warming period, as the Little Ice Age finished transformation to the Modern Warm Period in China and the Northern Hemisphere. The rapid warming could lead to the summer rainy season becoming $2-3$ pendates shorter.

Table 2

Rainy season length variation on inter-decadal scale

\begin{tabular}{llll}
\hline \multicolumn{2}{c}{ Decade $\begin{array}{l}\text { South Rim of plum Rain in } \\
\text { Xiangjiang river }\end{array}$} & $\begin{array}{l}\text { Middle reaches of } \\
\text { Yangtze river }\end{array}$ & $\begin{array}{l}\text { Middle reaches of } \\
\text { Yellow river }\end{array}$ \\
\hline 1860 & + & + & - \\
1870 & + & $\backslash$ & - \\
1880 & + & + & - \\
1890 & + & $\backslash$ & $\backslash$ \\
1920 & + & + & $\searrow$ \\
1930 & $\searrow$ & - & - \\
\hline
\end{tabular}

\section{Conclusion}

The flood season and the fluctuation at Sanmenxia on the Yellow River during 1766-1911, the Qinhe River during 1761-1911, and Yongding River during 1736-1911 were reconstructed based on the water level observation reports of the Qing dynasty. 5-point smoothed chronologies show that flood season was advanced and delayed during 1820-1860s and 1870-1880s, which correlates negatively with the temperature change of the loess plateau. This phenomenon is especially apparent in the 1880 s.

The cold phase on the loess plateau in 1880s agrees well with the cold phase in the Northern Hemisphere during 1820-1870 (Mann et al., 1998). This shows that the delay of the flood season is a feedback to the colder phase in the Northern Hemisphere.

The colder Northern Hemisphere period is not consistent with the warm summer temperature on the loess plateau. It is also inconsistent with the advance of the flood season revealed in this research. The results show that the beginning time of flood season of rivers in this area is related to the temperature fluctuation of the Northern Hemisphere, whereas it should be even more closely correlated with the summer temperature change on the loess plateau. This phenomenon could be a multiyear response to the change of the intensity of the monsoon of East Asia.

\section{References}

An, Z., 2000. The history and variability of the East Asian paleomonsoon climate. Quaternary Science Reviews 19, 171-187.

Ge, Q., Guo, X., Zheng, J., Hao, Z., 2008. Meiyu in the middle and lower reaches of the Yangtze River since 1736. Chinese Science Bulletin 53, 107-114 (in Chinese).

Ge, Q., Hao, Z., Tian, Y., 2011. The rainy season in the Northwestern part of the East Asian Summer Monsoon in the 18th and 19th centuries. Quaternary International 229, 16-23.

Ge, Q., Zheng, J., Fang, X., Man, Z., Zhang, X., Zhang, P., Wang, W.-C., 2003. Winter half-year temperature reconstruction for the middle and lower reaches of the Yellow River and Yangtze River, China, during the past 2000 years. Holocene 13 933-940.
Griffiths, J.F., 1994. Handbook of Agricultural Meteorology. Oxford University Press, New York, Oxford, p. 320.

Guo, Q., 1983. The summer monsoon intensity index in east Asia and its variation. Acta Geographica Sinica 38, 207-216 (in Chinese).

Guo, Q., Cai, J., Shao, X., Sha, W., 2004. Studies on the variations of East-Asian summer monsoon during AD 1873-2000. Chinese Journal of Atmospheric Sciences 28, 206-215 (in Chinese).

He, H., Zhou, J., Yu, Q., Tian, Y.Q., Chen, R.F., 2007. Flood frequency and routing processes at a Confluence of the Middle Yellow River in China. River Research and Applications 23, 407-427.

Huang, G., 2004. An index measuring the interannual variation of the East Asian summer monsoon-The EAP index. Advances in Atmospheric Sciences 21, 41-52.

Lee, E.-J., Jhun, J.-G., Park, C.-K., 2005. Remote connection of the northeast Asian summer rainfall revealed by a newly defined monsoon index. Journal of Climate 18, 4381-4393.

Lian, Y., Shen, B., Gao, Z., 2004. An exploration on the determination of East Asia summer monsoon index. Acta Meteorologica Sinica 62, 782-789 (in Chinese).

Lu, E., Chan, J.C.L., 1999. A unified monsoon index for South China. Journal of Climate $12,2375-2385$

Mann, M.E., Bradley, R.S., Hughes, M.K., 1998. Global-scale temperature patterns and climate forcing over the past six centuries. Nature 392, 779-787.

Pan, W., Liu, N., Zhuang, H., 2012. Study for the beginning time of flood season in the middle reaches of Yellow River, 1766-1911. Journal of Arid Land Resources and Environment 26 (5), 41-45 (in Chinese).

Shi, N., Zhu, Q., 1996. An abrupt change in the intensity of the East Asian summer monsoon index and its relationship with temperature and precipitation over east China. International Journal of Climatology 16, 757-764.

Sun, X., Chen, L., He, J., 2001. A discussion of the relationship between the east asian land-sea contrasts Index and the intensity of east asian summer monsoon. In: He, J.H., Ding, Y.H., Gao, H., Xu, H. (Eds.), The Ascertainment of the Onset Date of the East Asian Summer Monsoon as Well as Monsoon Indices. China Meteorological Press, Beijing, China, pp. 96-108 (in Chinese).

Tao, S., Chen, L., 1987. A review of recent research on the east asian summer monsoon in China. In: Cheng, C.P. Krishnamurti, YN. (Eds.), Monsoon Meteorology. Oxford University Press, Oxford, UK, pp. 60-92.

Tao, S.-Y., Li, J.-S., Wang, A.-S., 1997. Eastern Asian monsoon and the disaster of flood/drought. Disaster Reduction in China 7, 17-24 (in Chinese).

Wang, H., 2001. The weakening of the Asian monsoon circulation after the end of 1970 's. Advances in Atmospheric Sciences 18, 376-386.

Yang, Y., Man, Z., Zheng, J., 2007. Reconstruction of the starting time series of rainy season in Yunnan and the evolvement of summer monsoon during 1711-1982. Journal of Geographical Sciences 2, 1-10.

Yi, L., Yu, H.-J., Ge, J., 2012. Reconstructions of annual summer precipitation and temperature in north-central China since 1470 AD based on drought/flood index and tree-ring records. Climatic Change. http://dx.doi.org/10.1007/s10584011-0052-6.

Zhang, D., Liu, C., 2003. Continuation (1980-1992) of the yearly charts of dryness wetness in China for the last 500 years period. Meteorological Monthly 19, 41-45 (in Chinese).

Zhang, D., Li, X., Liang, Y., 2003a. Continuation (1992-2000) of the yearly charts of dryness/wetness in China for the last 500 year period. Journal of Applied Meteorological Science 14, 379-388 (in Chinese).

Zhang, Q., Tao, S., Chen, L., 2003b. The inter-annual variability of East Asian summer monsoon indices and its association with the pattern of general circulation over East Asia. Acta Meteorologica Sinica 61, 559-568 (in Chinese).

Zhao, H., Zhang, X., 1996. The relationship between the summer rain belt in China and the East Asia Monsoon. Meteorological Monthly 22, 8-12 (in Chinese).

Zhao, P., Zhou, Z., 2005. East Asian subtropical summer monsoon index and its relationships to rainfall. Acta Meteorologica Sinica 63, 933-941 (in Chinese).

Zheng, J., Wang, S., 2005. Assessment on climate change in China for the last 2000 years. Acta Geographica Sinica 60, 21-31 (in Chinese).

Zheng, Weiwei, 2010. A Study for Plum Rain Changing over the Middle Reaches of Yangtze River in Qing Dynasty. PhD thesis. Center for Historical Geography Studies of Fudan University, China.

Zhu, C., Lee, W., Kang, H., Park, C., 2005. A proper monsoon index for seasonal and interannual variations of the East Asian monsoon. Geophysical Research Letters 32, L02811. http://dx.doi.org/10.1029/2004GL021295.

Zhu, C., Zhou, X., Zhao, P., 2011. East Asian subtropical summer monsoon and flood season start time in China. Scientia Sinica (Terrae) 8, 1172-1181. 